\title{
High content cellular microarray for automated drug target deconvolution
}

\author{
Yong-Jun Kwon ${ }^{1 *}$, Hi Chul Kim', Nam Youl Kim', Seo Yeon Choi ${ }^{1}$, Sungyong Jung ${ }^{1}$, Auguste Genovesio ${ }^{2}$ \\ From Institut Pasteur International Network Annual Scientific Meeting \\ Hong Kong. 22-23 November 2010
}

Despite the promising paradigm offered by high-content screening, the concrete execution of hundred of thousands of visual cell-based experiments has remained highly challenging in terms of both statistical robustness and speed. An efficient computational method for cellular microarrays was developed at Institut Pasteur-Korea that allow for high speed, high content genome-wide siRNA screening. Details of the method and examples of data from genome-wide analyses will be featured in this presentation. In particular, we will demonstrate that the sudden ability to dramatically increase the number of experiments has created the opportunity for automated identification of a drug's target.

\section{Author details}

'Discovery Biology Group, Institut Pasteur Korea, Seongnam-si, 463-400, Korea. ${ }^{2}$ Image Mining Group, Institut Pasteur Korea, Seongnam-si, 463-400, Korea.

Published: 10 January 2011

doi:10.1186/1753-6561-5-S1-P76

Cite this article as: Kwon et al:: High content cellular microarray for automated drug target deconvolution. BMC Proceedings 2011 5(Suppl 1): P76.
'Discovery Biology Group, Institut Pasteur Korea, Seongnam-si, 463-400, Korea

Full list of author information is available at the end of the article
Submit your next manuscript to BioMed Central and take full advantage of:

- Convenient online submission

- Thorough peer review

- No space constraints or color figure charges

- Immediate publication on acceptance

- Inclusion in PubMed, CAS, Scopus and Google Scholar

- Research which is freely available for redistribution 